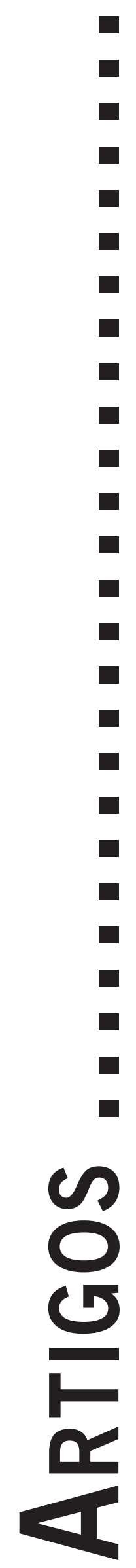




\title{
COMPREENDENDO OS TRANSTORNOS ALIMENTARES PELOS CAMINHOS DA GESTALT-TERAPIA
}

\author{
Understanding Eating Disorders by the Way of Gestalt-Therapy \\ Comprendiendo los Trastornos Alimentares por los Caminos de la Gestalt-terapia
}

ARLENE LEITE NuNES

ADRIANO HOLANDA

\begin{abstract}
Resumo: Os transtornos alimentares compreendem hoje um conjunto de doenças que afeta uma parcela significativa da população, em especial adolescentes. Sua apresentação sintomatológica aponta para a necessidade de um contato direto e concreto com a realidade experiencial do sujeito que sofre desses transtornos. A concepção de homem para Gestalt-terapia é a de um ser particular, concreto, único, consciente, responsável e relacional. Este artigo tem como objetivo discutir e lançar um olhar sobre os transtornos alimentares, apresentando a Gestalt-terapia como uma abordagem que possui recursos privilegiados para lidar com esse tipo de manifestação, a partir de uma percepção da doença como contextualizada e do sujeito como ser-no-mundo.

Palavras-chave: Anorexia Nervosa; Bulimia Nervosa; Transtornos Alimentares; Gestalt-terapia.
\end{abstract}

\begin{abstract}
Eating disorders are nowadays a group of diseases that affects an important amount of the population, specifically teenagers. Its symptomatology points to the necessity of a straight contact with the experimental reality of the subject that suffer these disorders. The conception of human being to Gestalt-therapy is a particular, concrete, unique, conscious, responsible and relational being. This article has the objective of discussing and taking a look over the eating disorders, presenting Gestalttherapy as approach that owns privileged resources to deal with this kind of manifestation, from a perception of the disease as contextualized and of the subject as a being-in-the-world.
\end{abstract}

Keywords: Anorexia Nervosa; Bulimia Nervosa; Eating Disorders; Gestalt-therapy.

Resumen: Hoy, los trastornos alimentares abarcan un conjunto de enfermedades que afectan a una parcela significativa de la populación, en especial a los adolescentes. Su presentación sintomatológica señala la necesidad de un contacto directo y concreto con la realidad experiencial del sujeto que sufre de esos trastornos. La concepción de hombre para la Terapia Gestalt es la de un ser particular, concreto, único, consciente, responsable y relacional. Este artículo tiene el objetivo de discutir y lanzar una mirada sobre los trastornos alimentares, presentando la Terapia Gestalt como una abordaje que posee recursos privilegiados para batallar con ese tipo de manifestación, a partir de una percepción de la enfermedad contextualizada y de sujeto como ser-en-el-mundo.

Palabras-clave: Anorexia; Bulimia; Trastornos de la Alimentación; Terapia Gestalt.

\section{Introdução}

Numa sociedade em que se privilegia o consumo e a imagem, observa-se um movimento crescente em torno do "ter", muitas vezes em detrimento de um "ser", onde o valor recai sobre o que as pessoas possuem mais do que sobre o que são ou o que representam. Erich Fromm (1980), em seu clássico Ter ou Ser já analisa o que aponta como o "fracasso da grande promessa”, referindo-se à idéia de um progresso ilimitado, que inclui o domínio da natureza e a abundância material como o que levaria à felicidade completa.

Associada a uma transformação na visão de homem e de mundo, segundo a qual a aparência tem uma importância cada vez maior, essa tendência de valorização do "ter" serve de solo fértil para acentuar os transtornos alimentares, extremamente vinculados ao ideal estético supervalorizado nos últimos tempos (Assumpção Jr, 2004).
Os transtornos alimentares constituem um conjunto de doenças que afetam, principalmente, adolescentes e adultos jovens do sexo feminino, provocando marcantes prejuízos biológicos, psicológicos e sociais e, conseqüentemente, propiciando o aumento das taxas de morbidade e mortalidade nesta população (Azevedo \& Abuchaim, 1998; American Psychiatric Association, 2000; Appolinario, 2000; Cordás, 2001, 2004; Cordas, Salzano \& Rios, 2004).

Em termos de magnitude e prevalência, os transtornos alimentares podem ser considerados doenças emergentes, características da sociedade pós-moderna. Estimase que, a cada ano, milhões de pessoas são acometidas por alguma modalidade de transtorno alimentar. Destas, mais de 90\% são adolescentes do sexo feminino (Castro \& Goldstein, 1995; Cintra \& Fisberg, 2004; Cordás, 2004; Dietz, 1990). 
Por apresentarem incidência crescente, esses transtornos demandam prevenção e tratamento por todos os meios possíveis. Trata-se de um dos transtornos do comportamento que mais matam no mundo - seja por desnutrição, problemas cardíacos e até mesmo suicídio. $\mathrm{Na}$ maioria dos casos, a pessoa com o transtorno não se considera doente, recusando, portanto, qualquer tratamento, mesmo com o surgimento de comorbidades.

Nos Estados Unidos, de acordo com Fisher et al. (1995), os transtornos alimentares constituem a terceira doença crônica não transmissível mais prevalente entre adolescentes, só perdendo para a obesidade e a asma. Dietz (1990) confirma citando que a anorexia e a bulimia nervosas estão entre os problemas nutricionais mais prevalentes em adolescentes. No Brasil não foram encontrados dados epidemiológicos de prevalência desses transtornos, conforme revisão realizada. Nunes et al. (2003), por sua vez, afirmam que não há estudos epidemiológicos de prevalência dos transtornos alimentares, não só no Brasil como também não existe em toda América Latina.

A etiologia dos transtornos alimentares é formada por um conjunto de fatores em interação, envolvendo componentes biológicos, psicológicos, familiares, socioculturais, genéticos e de personalidade. Não é possível definir uma causa única para que uma pessoa desenvolva esses transtornos, sendo que, diante dessa gama de fatores, se torna necessária uma abordagem integrada e multiprofissional, formada por, pelo menos, um psiquiatra, um clínico geral, um psicólogo e um nutricionista (Gorgati, Holcberg \& Oliveira, 2002).

Os principais transtornos alimentares são a Anorexia Nervosa e a Bulimia Nervosa, e embora sejam classificadas separadamente (tanto pelo DSM-IV-TR quanto pela CID-10), encontram-se intimamente relacionados por apresentarem psicopatologia comum: uma idéia prevalente envolvendo a preocupação excessiva com o peso e a forma corporal (medo de engordar), que leva as pacientes a se engajarem em dietas extremamente restritivas ou a utilizarem métodos inapropriados para alcançarem o corpo idealizado.

\section{Sobre os Transtornos Alimentares}

\section{A Anorexia Nervosa}

A anorexia nervosa é um transtorno alimentar no qual a pessoa se recusa a manter o peso corporal dentro do mínimo normal adequado para a idade e altura; mesmo apresentando peso abaixo do normal, ela sente muito medo de ganhar peso ou de se tornar gorda. A pessoa vivencia o peso ou a forma do corpo de maneira perturbada, influenciando impropriamente sua auto-avaliação e levando-a a negar o baixo peso corporal atual. E no caso de mulheres pós-menarca, ocorre a amenorréia - ausência de pelo menos três ciclos menstruais consecutivos (American Psychiatric Association, 2002).
Anorexia, em seu sentido vernáculo, significa redução ou perda do apetite, por um lado; e inapetência, por outro (Ferreira, 1993). Portanto, na realidade, não é o termo mais adequado para este transtorno, uma vez que não há perda real do apetite, pelo menos no início da doença. Desta forma, o termo alemão pubertaetsmagersucht mostra-se mais adequado, pois significa "busca da magreza por adolescentes" (Cordás, 2004).

A anorexia nervosa é classificada em dois tipos: restritivo e purgativo. No tipo restritivo, a pessoa não apresenta comportamento de comer compulsivamente ou de purgação regularmente, apresentando apenas comportamentos restritivos, associados à dieta. Já no tipo purgativo, ocorrem regularmente episódios de comer compulsivamente ou de purgação como vômitos auto-induzidos, além de uso inapropriado de laxantes e diuréticos (Appolinário \& Claudino, 2000; American Psychiatric Association, 2002).

A anorexia nervosa normalmente começa na infância ou na adolescência, a partir de uma restrição dietética progressiva, segundo a qual os alimentos considerados engordativos são eliminados. A pessoa passa a apresentar insatisfação com o corpo e sentir-se obesa - embora muitas vezes esteja emagrecida - além de sentir medo de engordar, que é uma característica essencial deste transtorno. Aos poucos a pessoa passa a viver apenas em função da dieta, sendo o curso da doença caracterizado por uma perda progressiva e continuada de peso, bem como por mudanças no padrão alimentar, que se tornam mais e mais secretas, apresentando muitas vezes características ritualizadas e bizarras (Appolinário, 2000; Beumont, 2002).

Neste transtorno podem surgir várias complicações médicas, especialmente decorrentes da desnutrição e dos comportamentos purgativos, tais como anemia, alterações endócrinas, osteoporose, alterações hidroeletrolíticas, dentre outras. É comum encontrar quadros psiquiátricos associados a este transtorno, principalmente transtornos do humor, ansiedade e/ou personalidade (Appolinário \& Claudino, 2000; American Psychiatric Association, 2002).

\section{Bulimia Nervosa}

O termo bulimia foi criado por Russell (citado por Cordás, 2004) e tem origem na união dos termos gregos boul (boi) ou bou (grande quantidade) com lemos (fome), assim, é uma fome muito intensa ou suficiente para devorar um boi. Assim, a bulimia nervosa é um transtorno alimentar no qual ocorrem episódios recorrentes de consumo alimentar compulsivo, chamados de crises ou episódios bulímicos, com ingestão de alimentos muito maior do que a maioria das pessoas consumiria em condições e circunstâncias similares, em pequeno intervalo de tempo, associado à sensação de perda de controle so- 
bre o comportamento alimentar (American Psychiatric Association, 2002).

Esses episódios de compulsão alimentar são os principais sintomas da bulimia nervosa. São normalmente decorrentes de uma dieta para emagrecer, podendo estar inicialmente relacionado à fome, mas depois, quando o ciclo compulsão alimentar-purgação está instalado, pode acontecer em todas as situações que geram sentimentos negativos, como frustração, tristeza, ansiedade, tédio ou solidão. Esses episódios geralmente ocorrem escondidos, acompanhados de sentimentos de vergonha, culpa e desejos de autopunição, sendo que a quantidade de calorias ingerida durante um episódio pode variar muito, embora a média seja de 2 mil a 5 mil calorias (Appolinário \& Claudino, 2000; Azevedo \& Abuchaim, 1998).

É interessante observar que entre um episódio bulímico e outro a pessoa normalmente restringe o consumo calórico total, selecionando alimentos com baixas calorias e evitando alimentos que perceba como engordativos ou que ativariam um ataque de hiperfagia (American Psychiatric Association, 2002). Após tais episódios, ocorrem comportamentos compensatórios inadequados, com a intenção de prevenir o ganho de peso, como uso inapropriado de diuréticos, laxantes, enemas ou outros medicamentos, jejuns e exercícios excessivos, vômitos autoinduzidos, que ocorrem em $90 \%$ dos casos. Além disso, a forma e o peso corporal influenciam de maneira indevida a auto-imagem (Appolinário \& Claudino, 2000; American Psychiatric Association, 2002).

A bulimia nervosa é classificada em dois tipos de acordo com o método compensatório adotado. No tipo purgativo, os métodos são mais invasivos: ocorrem vômitos auto-induzidos, uso indevido de laxantes, diuréticos ou enemas regularmente. No não-purgativo, a pessoa realiza jejuns ou pratica exercícios em excesso, mas não induz vômito e nem faz uso de medicamentos de forma inadequada regularmente (American Psychiatric Association, 2002).

A bulimia nervosa apresenta várias complicações médicas, decorrentes principalmente da utilização dos métodos compensatórios como erosão dos dentes, alargamento das parótidas, esofagites, hipopotassemia e alterações cardiovasculares, entre outras. Como ocorre na anorexia nervosa, é também comum haver quadros psiquiátricos associados à bulimia nervosa, especialmente os transtornos do humor, ansiedade e personalidade. Em algum momento da evolução clínica da doença, várias pessoas (cujo índice varia de 46\% e 89\%) apresentam transtorno depressivo associado (Azevedo \& Abuchaim, 1998; Appolinário \& Claudino, 2000).

\section{Dados Estatísticos}

A anorexia nervosa ocorre predominantemente em mulheres jovens, sendo que a prevalência varia entre
0,5\% e 3,7\%, havendo dois picos de incidência, um aos 14 e outro aos 17 anos. Nos Estados Unidos este número se encontra em torno de $0,48 \%$; sendo assim, estimase que há cerca de um caso de anorexia nervosa a cada 200 adolescentes do sexo feminino entre 15 e 19 anos. Outros estudos indicam que incidência de anorexia nervosa se encontra em torno de oito por 100.000 pessoas por ano, principalmente entre mulheres na faixa etária de 15 e 24 anos de idade (American Psychiatric Association, 2000; Appolinário \& Claudino, 2000; Manley, Rickson \& Standeven, 2000).

Em revisão bibliográfica realizada por Pinzon \& Nogueira (2004) sobre taxas de incidência, recuperação e mortalidade relacionadas à anorexia nervosa, foram identificados os seguintes valores: com relação às taxas de incidência, estima-se que, entre mulheres, seja de aproximadamente 8 por 100 mil indivíduos numa população pareada por ano. Normalmente, depois de intervenções terapêuticas, há recuperação completa em torno de 50\% dos casos, intermediária em torno de $30 \%$, enquanto que cerca de 20\% dos casos apresentam recuperação desfavorável. Recaídas ocorrem em torno de $12 \%$ a 27\% dos casos, apresentando taxa de cronicidade aproximada de 20\%.

Na revisão em questão, pesquisas mostraram que as taxas brutas de mortalidade variam de $5 \%$ a $20 \%$, e as comparativas são de 6 a 12,82 vezes maiores do que as esperadas para população com características pareadas, em pesquisas de médio e longo prazo, respectivamente. Entre as principais causas da mortalidade encontramos as complicações derivadas da própria anorexia nervosa (com taxas de 50\% a 54\%), o suicídio (entre 24\% a 27\%) e causas desconhecidas (de 15\% a 19\%).

Com relação à bulimia nervosa, as taxas de incidência, recuperação e mortalidade revelam os seguintes valores: a taxa de prevalência deste transtorno encontra-se entre 1,1\% a 4,2\%. A taxa de incidência é de aproximadamente 13 por 100 mil indivíduos numa população pareada por ano. A bulimia nervosa aparentemente apresenta uma evolução mais favorável que a anorexia nervosa, apresentando índices de recuperação total entre 50\% e 70\% dos casos, enquanto que os de recaída variam de $30 \%$ a $50 \%$. As taxas brutas de mortalidade variam de $0,3 \%$ a $3 \%$, encontrando-se bem abaixo dos números da anorexia nervosa (Pinzon \& Nogueira, 2004).

\section{Diagnóstico Diferencial}

No senso comum costuma-se associar episódios de compulsão alimentar, vômitos auto-induzidos e uso indevido de laxantes e diuréticos exclusivamente à bulimia nervosa e, por outro lado, à anorexia nervosa associa-se apenas uma imagem de uma pessoa que não come, super-emagrecida. Isso é verdade, mas não é toda a verdade. Há mais alguns fatores a serem considerados para que se possa fazer um diagnóstico diferencial. 
Na bulimia nervosa, na maioria dos casos (em torno de 70\%), a pessoa consegue manter o peso dentro do limiar de normalidade; $15 \%$, aproximadamente, ficam um pouco abaixo do peso, e outros $15 \%$ podem até estar acima do peso. Não há o desejo incontrolável de emagrecer, a amenorréia não é um marco, como no caso da anorexia nervosa, e a distorção da imagem corporal não é tão intensa (Appolinário \& Claudino, 2000; Cordás, Salzano \& Rios, 2004; Johnson \& Connors, 1987).

A questão que se coloca é: "quem sofre de transtornos alimentares?". E a resposta é simples: uma pessoa, um ser humano. Precisamos, então, ter claro quem é esta pessoa, este ser humano com quem vamos trabalhar. Para tal é preciso uma definição de "ser humano" que dê conta da complexidade de sua experiência, de modo que possamos alcançar o cerne do problema.

Um dos fatos dignos de nota é que este ser que sofre de transtorno alimentar é um ser particular, concreto, único, consciente, responsável, com formas próprias e, além disso, é um ser relacional. Logo, independente de quantas pessoas com determinado transtorno seja atendido nos consultórios, cada uma delas vai vivenciar seu transtorno de forma particular.

Ao se trabalhar com transtornos alimentares, não se pode considerar simplesmente o "transtorno" isoladamente, sem considerar o meio no qual a pessoa se encontra, não sendo possível ignorar os estímulos que ela recebe. Este ser que sofre é antes de tudo um ser de relações, e é a partir dessas relações que estabelece com o mundo que constrói sua vida, sua existência e sua própria concepção de mundo e de si. Esta é a essência desse ser que sofre de transtornos alimentares (Mattos, 2000).

Este ser humano é um todo, composto de vários aspectos: físicos, mentais e espirituais, e está imerso em uma sociedade na qual interage, influenciando e sendo influenciado, modelando-a e sendo modelado através de seus relacionamentos. Não se pode, então, vê-lo fora do seu contexto. É fundamental conhecer a pessoa e não apenas seus sintomas e sua doença; atender à pessoa inteira e não simplesmente tratar a patologia; não receber e atender uma "anoréxica", mas procurar conhecer esse ser por inteiro que está com o problema, levando em conta tudo o que o cerca para então trabalhar com ele, como um indivíduo completo (Maldonado \& Canella, 2003).

Deve-se, portanto, olhar para cada pessoa com estes transtornos como um ser único, suspendendo conceitos pré-estabelecidos sobre o que é ou como deveria se apresentar um transtorno alimentar, e compreender esta pessoa a partir da sua própria vivência. É importante ter esse conhecimento teórico de fundo, mas a teoria é apenas uma das formas de se ver este fenômeno, o transtorno alimentar. Quando vamos para o contato com o nosso cliente é fundamental deixarmos de lado por alguns momentos nosso arcabouço teórico e vermos como é o transtorno alimentar para ele, como é para cada um.
É fundamental também compreender não apenas o que acontece no corpo dessa pessoa, mas também o que ocorre no emocional: uma vez que se considere o ser humano como um todo, ele deve ser visto e compreendido como tal. Ou seja, nem considerar exclusivamente a doença, nem exclusivamente o emocional, mas considerar os dois lados desse todo que é o indivíduo, de forma integrada. O ser humano não é apenas um ser que sente. $\mathrm{Ou}$ apenas um ser que se alimenta. Ele é um ser que sente e que se alimenta. Não é possível olhar o transtorno isolado do indivíduo, nem o indivíduo isolado de seu meio. Pessoas com anorexia ou bulimia normalmente não apresentam esses comportamentos apenas em relação à comida: relacionam-se dessa forma frente à vida, e aos sentimentos, como um todo.

\section{Os Transtornos Alimentares sob a Ótica da Gestalt- Terapia}

Quando se fala em transtornos alimentares sob o olhar da Gestalt-terapia, se fala em adoecer. Considerando a base fenomenológico-existencial desta abordagem e compreendendo o homem a partir de sua existência, subjetividade e potencial de constante crescimento e auto-regulação, o adoecer é visto como uma etapa de um ajustamento criativo disfuncional, capaz, muitas vezes, de proteger a pessoa de determinadas experiências insuportáveis (Polito, 1999).

O que é um ajustamento criativo? E como pode ser entendido um ajustamento criativo "disfuncional"? Essa idéia nos remete a uma consideração diferenciada da psicopatologia, não mais como categoria nosológica ou manifestação sintomatológica, mas como processo e modo-deser ou existir, numa perspectiva que nos aproxima da tradição fenomenológica de psicopatologia e psiquiatria.

A Gestalt-terapia se enquadra nesse movimento quando fala de "processos psicopatológicos" como em Perls, Hefferline \& Goodman (1997). Segundo Tenório (2003), "os teóricos da Gestalt Terapia desenvolveram uma compreensão dos processos psicopatológicos do desenvolvimento a partir dos estudos dos processos de auto-regulação organísmica (...)” (p. 34). O ser humano tende a se autoregular para melhor se adaptar às suas relações com seu meio circundante. Porém, nem sempre a auto-regulação dá conta de todas as situações, tornando-se necessário que a pessoa faça "algo mais". Esse "algo mais" é o ajustamento criativo, que representa:

o processo através do qual o indivíduo se relaciona de forma ativa e criativa com o meio na busca da satisfação plena de suas necessidades, ou seja, na busca de equilíbrio, sendo, então, um processo de adaptação em que não há primazia de um sobre o outro, e sim uma negociação entre ambas as partes, como um acordo que se cria entre o indivíduo e meio (Mattos, 2000, p.16). 
Um ajustamento criativo pode, muitas vezes, parecer estranho num primeiro momento, pois dá mais ênfase ao criativo do que ao adaptativo. Porém, quando lembramos da auto-regulação e que cada pessoa é única e singular, podemos considerar que cada um vai construir seu estar no mundo da melhor forma possível, de acordo com suas condições de momento. Um ajustamento criativo, visto fora de seu contexto, nem sempre parece a melhor opção, mas certamente foi o melhor que aquele indivíduo conseguiu naquele momento de acordo com a percepção que tinha da situação e com os recursos que possuía. Considera-se então que toda atitude, comportamento, escolha e construção do indivíduo são uma tentativa de se equilibrar diante de algo que o desequilibra, tendo desta forma uma função na relação que ele estabelece com o meio (Perls, 1997; Mattos, 2000).

Essa reflexão releva, em particular, modos de funcionamento ou modos de enfrentamento no cotidiano. $\mathrm{Na}$ tradição clássica de apropriação da psicopatologia, temos, segundo Canguilhem (2000), que a medicina clássica ocidental oscila entre dois pólos de consideração: um pólo ontológico - que se apropria e considera o ser-doente - e um pólo mecanicista - que ignora o ser próprio do doente e toma a doença (ou o sintoma) como objeto em si, concreto e objetivo. Porém, o mesmo autor afirma que concepções dinâmicas de saúde remontam à Antiguidade, tendo em Hipócrates um defensor de uma concepção "totalizante" da doença (Canguilhem, 2000). A própria concepção de physis - ou "natureza" - na Antiguidade Grega a identifica com harmonia e equilíbrio. A perturbação desse equilíbrio é que seria a “doença”. Nesta direção, a doença está no homem todo e é o homem todo.

Já nestas concepções encontramos uma oposição entre "normalidade" (como enquadre de generalidades) e "anormalidade" (como o que destoa do geral), e nisto percebe-se que, ao destoar daquilo que se considera no coletivo como o "normal”, o indivíduo corre o risco de ser considerado "anormal". Em outras palavras, patologiza-se o diferente. Nas palavras de Canguilhem (2000):

O alienado 'não se enquadra' não tanto em relação aos outros homens, mas em relação à própria vida; não é tanto desviado, mas, sobretudo diferente. É pela anomalia que o ser humano se destaca do todo formado pelos homens e pela vida. É ela que nos revela o sentido de uma maneira de ser inteiramente 'singular' e o faz primitivamente, de um modo muito radical e impressionante (Canguilhem, 2000, p.89, grifos nossos).

Quando Foucault e Canguilhem analisam a história da Medicina ocidental, apontam para a dominância da "abordagem quantitativa" desta, onde a cura significa levar de volta à norma, em geral alicerçado sobre seu conhecimento de fisiologia. Assim, o "diferente" ou aquele que funciona de modo inabitual, insólito ou atípico tende a ser segregado (Foucault, 1984, 1991; Goffman, 1996; Holanda, 2001).
Neste caminho, a tradição fenomenológica aponta então para a psicopatologia como "modo-de-ser", como modo de existir no mundo. Esta tradição fenomenológica aponta para as relações de diferença (diversidade) e semelhança (similaridade), opostas à normatização ou normalização que dominam a medicina tradicional mecanicista apontada por Canguilhem (2000), e que considera o homem como objeto. Na perspectiva fenomenológica, o ser-doente é diferente de "ser um doente”, já que a doença não mais se localiza em algum lugar, mas passa a ser condição humana (Holanda, 2001).

A Gestalt-terapia tem uma concepção similar, mesmo que algumas interpretações concebam a psicopatologia como localizada internamente ou descontextualizada. Como aponta Carvalho (2008), a abordagem gestáltica visa as potencialidades e a chamada "sabedoria organísmica” - conceito compartilhado com a tradição da psicologia humanista americana, notadamente em Rogers - e considera o estado "saudável” como um "processo permanente de manutenção de equilíbrios e de ajustamento às condições, sempre flutuantes, do meio interno e externo" (Carvalho, 2008, p. 80).

Gestalt-terapia fala de um "funcionamento ótimo da personalidade" - nos dizeres de Delisle (1991) - com ênfase nos aspectos saudáveis, ou seja, no processo, no funcionamento. Na Gestalt-terapia, o princípio que impera e regula a leitura do fenômeno psicopatológico deve ser o da "totalidade" ou "globalidade", o de que "tudo é um todo" (Clarkson, citado por Holanda, 1998), e totalidade, aqui, é interação, contexto, dinâmica, dialética (Holanda, 1998). A perspectiva aqui é interacionista e existencial, onde "no centro da patologia está escondida a normalidade" (Van Dusen, citado por Holanda, 1998).

(...) pode-se afirmar que a psicopatologia então, não é concebida como uma categoria limitante da experiência que apenas compromete o indivíduo, pois a Gestalt-terapia não negligencia aspectos saudáveis preservados por ele; antes, encara o processo psicopatológico por um viés positivo de ajustamento em situações insustentáveis ao self (Carvalho, 2008, p. 80).

Portanto, o processo saúde e doença, em Gestaltterapia é essencialmente dialético (Holanda, 1998), dado que - tanto a saúde, quanto a psicopatologia - são relacionais. Adoecer é o mesmo que desarmonia relacional (Holanda, 1998; Carvalho, 2008). Perls, Hefferline \& Goodman (1997) apontam que o organismo se vale de resistências para a defesa do self, sendo o bloqueio uma função de preservação. Portanto, segundo o texto clássico da teoria clínica gestaltista, um "bloqueio de contato" é, inicialmente, uma estratégia saudável. Temos aqui uma concepção de "desajustamento" que é adaptativo e, por outro lado, uma concepção de "ajustamento" que pode ser considerado desadaptativo. É nesta direção que Carvalho (2008) aponta para os ajustamentos do tipo neurótico e os 
ajustamentos do tipo psicótico, como modelos de compreensão da psicopatologia, numa perspectiva gestáltica.

Ainda nesta direção, o conceito de "criatividade" em Gestalt-terapia, remete a modos diferenciados de enfrentamento do mundo, visando à auto-regulação. Perls, Hefferline \& Goodman (1997) apontam como "criativos" aqueles mecanismos que resultam da relação intencional do indivíduo com o mundo, em contraste com os ajustamentos conservativos, e que dizem respeito às funções reguladoras de caráter fisiológico.

Temos, portanto, de concluir que todo contato é criativo e dinâmico. (...) Todo contato é ajustamento criativo do organismo e ambiente. Resposta consciente no campo (como orientação e como manipulação) é o instrumento de crescimento no campo (...). Podemos, portanto, definir: a psicologia é o estudo dos ajustamentos criativos. Seu tema é a transição sempre renovada entre a novidade e a rotina que resulta em assimilação e crescimento. Correspondentemente, a psicologia anormal é o estudo da interrupção, inibição ou outros acidentes no decorrer do ajustamento criativo (Perls, Hefferline \& Goodman, 1997, p. 44-45. Grifos no original).

Os transtornos alimentares podem ser considerados ajustamentos criativos, na medida em que possibilitam que a pessoa não tenha que lidar nem com as tensões nem com o meio. Diante disto, é importante descobrir para qual ajustamento criativo o transtorno serve e como a pessoa se apropria do transtorno alimentar como mecanismo de evitação. Como o foco fica com os comportamentos - comer, vomitar, contar calorias - a pessoa se desapropria de questões subjetivas que, muitas vezes, são o cerne do conflito, como o enfrentamento do cotidiano, angústias e ansiedades, sexualidade, etc., usando os esses comportamentos como um muro protetor entre a pessoa e o mundo (Angermann, 1998; Teixeira, 2004a, 2004b).

Quando a pessoa vai para a terapia, ela chega com uma queixa, que é uma parte de um todo. Tudo que se vive é vivido no corpo: as emoções, tristezas, alegrias e dores. As manifestações estão no corpo: o sorriso, a lágrima, a contração muscular. O organismo participa de tudo, tendo uma tendência de se auto-regular, de procurar satisfazer suas necessidades de equilíbrio, de buscar o que é melhor para ele naquele momento, com o que ele tem disponível para tal. Quando se considera exclusivamente a queixa, perde-se a oportunidade de ver esse outro lado que, na maioria das vezes, nem a própria pessoa conhece.

Considera-se então que, numa situação de emergência, a pessoa procura a melhor maneira possível de lidar com o que se apresenta (função de segurança): contenção de energia ou substituição da necessidade. É necessário suprir a excitação da necessidade genuína, e a energia vai para a contenção. O problema ocorre quando a atitude que era consciente e controlada passa a ser crônica, repetida, irrefletida e, portanto, cristalizada. Nesse momento, perde sua função primária de ajustamento para ser apenas uma adequação limitada ao contexto, impe- dindo a pessoa de agir de formas diferentes aos distintos contextos. A questão fundamental é que cada nova situação demanda um ajustamento igualmente diferenciado; sendo a cristalização ou sedimentação (engessamento do ato) uma estratégia adaptativa de momento, mas não replicável em situações diferenciadas.

Saúde, em Gestalt-terapia, é sinônimo de comportamento livre, espontâneo, criativo e fluido. Precisamos lembrar que estamos tratando uma pessoa única, não apenas um tipo de doença. Além da doença, a pessoa tem também sua expressão verbal, não verbal, movimentos do corpo, mudanças físicas. Tudo no ser humano é profundo em significados, e temos que manter em mente que não é o sintoma que está em terapia, mas o indivíduo como um todo, sendo necessário então ir além deste sintoma, para que seja possível trabalhar com os processos que o mantêm (Perls, 1997; Panazzolo, 2002).

O estar doente é um processo e não algo definitivo, sem perspectiva de transformação. Ao contrário, ele é visto como uma experiência peculiar do indivíduo (Polito, 1999).

A partir disso, podemos ver os transtornos alimentares como um sintoma; e o que é um sintoma? É um sinal, um signo, que remete a um significado, mas é antes de tudo uma forma de ajustamento. É a expressão fenomenal do sujeito que aparece enquanto tal, ou seja, o sintoma apresenta o sujeito próprio da sua manifestação, dado que mostra (presentifica) aquele que o "sente". Mas o sintoma é também uma forma de ajustamento, mas que não está de acordo com as necessidades reais e atuais do organismo. Contudo, não se pode simplesmente eliminá-lo, uma vez que ele é algo que foi desenvolvido pelo organismo. É importante entender o sentido existencial do sintoma na vida da pessoa, pois ele "representa uma expressão do homem como um todo, representa uma determinada configuração das partes desse todo. Com isso, podemos dizer que o homem não tem um sintoma, ele é o seu sintoma" (Tellegen, 1984; Teixeira, 2004a, 2004b; Mattos, 2000).

Uma vez que o indivíduo é visto como um todo, ele é tratado como um todo, não como um sintoma apenas: não será tratada então, apenas uma dor de cabeça, mas uma pessoa com queixa de dor de cabeça. Uma vez que não há problemas isolados em nosso corpo, não deveria haver tratamentos isolados. Esse sintoma fala alguma coisa a respeito da vida da pessoa, como se fosse uma "mensagem"; então é importante que a pessoa compreenda a serviço do que ele se instalou e está presente em sua vida neste momento de sua existência, que lugar ele está ocupando em sua vida (Rodrigues, 2000).

Muitas vezes, é o sintoma o único suporte que a pessoa tem e tirá-lo pode deixar a pessoa sem alicerce, o que a levará ao desenvolvimento de novos sintomas. Uma terapia que só foca o sintoma não vê o que a doença apresenta da realidade existencial da pessoa. Como ressalta Rodrigues (2000, p.133) "na medida em que enfocamos a totalidade da pessoa, com seu sentido vivencial, a eficá- 
cia terapêutica poderá trazer um resultado mais profundo do que um tratamento que só atue sobre a doença ou sobre o sintoma".

"Fazer regime tornou-se parte de nossa cultura a tal ponto que as mulheres costumam fazê-lo sem levar em conta seu peso real. Passaram a considerar que, qualquer que seja seu peso, o melhor seria pesar menos" (Hirschmann \& Munter, 1992, p.13). Na anorexia nervosa, a perda de peso costuma ser vista como uma grande conquista e um sinal de extraordinária disciplina pessoal, enquanto que o ganho de peso é percebido como um inaceitável fracasso do autocontrole (Panazzolo, 2002). Observa-se ainda uma distorção acentuada, quase ilusória, associada a um medo enorme dessas pessoas de tornarem-se obesas acentuando a busca pela magreza, embora o medo não pareça ter fundamento real: estudos (Angermann, 1998; Nunes, 2006) indicam que a maioria das pessoas com anorexia nervosa nunca teve um problema de peso e nem histórico familiar de obesidade.

Ainda a respeito da forma de experienciar o corpo, é sabido que há neste transtorno grande distorção da imagem corporal. Quando se fala nesse tema, normalmente se imagina uma pessoa magra que ao se olhar no espelho se "vê" gorda. Walsh \& Garner citado por Angermann (1998) trazem um outro ponto de vista: não é que a pessoa magra se "vê" gorda, na verdade ela pode perceber seu tamanho com precisão, o problema está no julgamento que faz sobre o tamanho que vê. Diante desses dados, podese perceber que a problemática da anorexia nervosa vai além da questão do peso.

A bulimia pode ser uma metáfora, onde a fome fisiológica se transmuta em fome de relação, de pertencimento, cuja satisfação a pessoa não encontra no meio e busca na comida. Um dos aspectos interessantes da terapia com bulímicos é o questionamento sobre a quantidade de comida ingerida durante um episódio de compulsão, pois muitas pessoas nem ingerem quantidades de alimento tão grandes e podem vomitar depois de pequenas porções, como depois de comer um pedaço de pizza, por exemplo. Mesmo o tamanho da porção sendo considerado "normal" ou aceitável, o elemento crítico é que a pessoa não pretendia "comer pizza", então o ato é percebido como uma compulsão, o que induz o vômito. Logo, observa-se que o vômito não segue necessariamente apenas episódios de compulsão, mas pode seguir qualquer ingestão de comida (Angermann, 1998).

Pode-se observar que pessoas com transtornos alimentares passam muito tempo contando calorias, desenvolvendo horários elaborados para exercícios, planejando os detalhes do próximo episódio compulsivo e/ou purgativo, examinando seus corpos na busca de defeitos. Muito tempo e energia são gastos com isto. Deste modo, é importante que se compreenda o que se está tentando evitar entrar em contato focando toda sua energia para preocupações com a comida, o peso e o corpo. É preciso ampliar o foco do seu mundo interno para o mundo externo, de modo a diminuir essas obsessões. Ao entrar em contato com o que realmente está acontecendo e o que este sintoma está encobrindo, pode ser possível descobrir novas formas para lidar com a comida, assim como com suas outras relações (Angermann, 1998; Teixeira, 2005).

Diante disso, é importante correlacionar o ato, o sintoma, questionando de que forma eles podem estar relacionados com outros fatos ou acontecimentos na vida da pessoa. Esta precisa tomar consciência da forma que estabelece sua relação com a comida, compreender para que serve esse padrão na sua vida como um todo. Esse padrão de alimentação representa uma escolha - é o melhor que o indivíduo está fazendo com os recursos que ele possui.

As comidas têm um significado diferente para cada um. Desta forma, ao invés de simplesmente modificar um hábito alimentar e com isto eliminar o sintoma, deve-se possibilitar que a pessoa compreenda o significado que essa comida tem, bem como o lugar que ocupa na vida dela, pois, muitas vezes, elas têm segredos com elas mesmas e nem sempre percebem que há algo de errado em seu padrão alimentar (Gaspar, 2004a, 2004b; Saikali, 2004).

É importante, portanto, compreender, aceitar este padrão alimentar para possibilitar uma re-configuração dessa relação tanto com a comida quanto com o mundo, ou seja, ir além do controle alimentar. O sintoma protege, é um pedido de ajuda: mesmo diante de situações que parecem caóticas, o indivíduo está fazendo o melhor que ele pode naquele momento, tendo em vista que não consegue se relacionar com o mundo de outra maneira.

A pessoa precisa se tornar curiosa por ela mesma. É preciso compreender o sentido dos sintomas. Ela vai entender que o comer compulsivo, o não comer, o vomitar estão encobrindo alguma coisa. É preciso levá-la para este despertar, do que estava sentindo quando teve a crise (Teixeira, 2004a, 2004b).

Outro ponto fundamental a se considerar no processo terapêutico é o estabelecimento do vínculo terapêutico. É comum pessoas com transtornos alimentares apresentarem postura de defesa, de afastamento com quem querem ajudá-los, resistência no estabelecimento do vínculo, tendo em vista que, como não consideram que têm um problema, não precisam de ajuda.

Porém, como partimos do princípio que as pessoas estabelecem relações com o mundo de modos diversos, a comida representa igualmente uma experiência mundana. Usando a relação com o alimento como metáfora, trata-se de não mais lidar com os aspectos formais da alimentação (controle, regulação, etc.) apenas, mas lidar com suas relações mais amplas com o mundo e a vida; trabalhar com seus significados e sentimentos dirigidos à sua existência como ser-no-mundo.

É de fundamental importância ter a presença da família na terapia - trazer a família para o processo - dado que a consideração do transtorno alimentar por uma ótica sistêmica, nos coloca diante das relações de campo, ou seja, o sintoma não mais é tratado por uma perspectiva 
subjetivista, mas inserida no contexto intersubjetivo. É comum que os familiares cheguem ao processo terapêutico desorientados, envergonhados, com sentimentos de culpa; há mesmo casos em que se encontram isolados, sem hábitos alimentares regulares. Muitas vezes a própria família, o meio, os valores da sociedade, contribuem para o reforço e a manutenção do problema, dificultando na recuperação (Saikali, 2004).

Deve-se considerar que apenas compreender o caso e sentir o corpo e as emoções não resolve totalmente o problema, embora faça com que uma solução seja novamente possível. Mas se o ambiente social não acolher a mudança, se o paciente não puder ajustá-lo a si próprio, então poderá novamente voltar ao seu problema (Perls, Hefferline \& Goodman, 1997).

\section{Considerações Finais}

Uma das bases da Gestalt-terapia é a fenomenologia. Na perspectiva fenomenológica, toda interpretação é contextualizada e circunscrita. Trata-se, pois, de uma abordagem compreensiva, onde as "leituras" partem das relações intencionais e se encontram nestas.

A partir desta perspectiva compreensiva, o trabalho terapêutico deve visar a realidade concreta e particular de cada sujeito, como um existente. Os objetivos e a forma de trabalho com pessoas que apresentam transtornos alimentares são similares àqueles com pessoas que apresentam qualquer outra queixa. Isso porque, lembramos, em qualquer dessas situações, estamos atendendo à pessoa, e não à "doença”. Ainda assim, existem cuidados especiais e, de modo geral, pode-se dizer que a meta do trabalho psicoterápico em Gestalt-terapia nos transtornos alimentares é a "conscientização da dinâmica patológica que fomenta estes distúrbios, visando ampliar as possibilidades existenciais do paciente, que no momento se encontram cristalizadas" (Panazzolo, 2002).

A Gestalt-terapia contribui muito na compreensão do emocional da pessoa com transtorno alimentar, especialmente por sua visão holística do ser humano, que evita privilegiar somente o racional e verbal, e cuida também da linguagem corporal. É uma excelente abordagem para trabalhar com transtornos alimentares, pois a concepção de um processo terapêutico calcado na relação intersubjetiva recoloca o sujeito do terapeuta em relação direta com a pessoa do cliente e, no caso dos transtornos alimentares, o trabalho experiencial - como resgate do vivido de cada um - é de fundamental importância, já que se observa que a maioria das pessoas que apresentam esse tipo de transtorno aponta para uma relação limitada ou desconectada com seu próprio corpo e sentimentos. Além disso, a Gestalt-terapia, por focar nos aspectos saudáveis, resgata os aspectos criativos de cada um, guardando o cuidado de se lidar com as polaridades (Perls, Hefferline \& Goodman, 1997; Teixeira, 2004a, 2004b; 2005).
Nesta abordagem, terapeuta e cliente juntos focam no “como”, não no "por que” a pessoa está onde está. Como modo de aumentar a awareness e integrar partes fragmentadas do self, os clientes com transtornos alimentares apontam para uma demanda por experienciar seus conflitos de forma direta. Embora o terapeuta esteja ativo neste processo, a interpretação de eventos, experiências e até mesmo de sonhos é responsabilidade do cliente. Mudança e metamorfose não são planejadas ou exigidas no processo terapêutico. É possibilitado ao cliente revelar-se: tornarse quem ele realmente é, gastando menos energia em ser quem ele não é (Angermann, 1998).

Desta forma, pode-se descrever como caminho da saúde:

[...] o resgate da consciência sobre o seu corpo, pensamentos e sentimentos, de forma a tornar-se uma presença consciente. Aprender a assumir responsabilidade sobre suas ações e escolhas. Ser capaz de criar metas e reconhecer limites para dar sentido a sua existência. Exercer a auto-regulação de forma consciente para poder hierarquizar as suas necessidades e se ajustar criativamente ao meio (Antony \& Ribeiro, 2004, p.134).

\section{Mensagem Final}

Em uma entrevista a Juste (2004), uma moça de vinte e três anos, ex-anoréxica desabafa:

O que as pessoas precisam entender é que anorexia, bulimia e compulsão alimentar são doenças e precisam ser tratadas como tais. Uma menina anoréxica precisa ser levada a sério assim como uma menina com câncer deve ser. Não está sob o poder dela deixar de se sentir gorda, de vomitar, de fazer jejum, assim como não está sob o poder da menina com câncer fazer com que seu tumor desapareça.

Este depoimento aponta o quanto os transtornos alimentares devem ser vistos com seriedade, como aponta a literatura (Dietz, 1990; Castro \& Goldstein, 1995; Azevedo \& Abuchaim, 1998; Appolinario, 2000; Cordás, 2001, 2004; Cordas, Salzano \& Rios, 2004; Cintra \& Fisberg, 2004, Cordás, 2004;). A falta de conhecimento ou o não reconhecimento desses transtornos como uma realidade só prejudica ainda mais quem sofre com eles podendo, até mesmo levá-lo a óbito.

\section{Referências Bibliográficas}

American Psychiatric Association (2000). Practice Guideline for the Treatment of Patients with Eating Disorders. American Journal of Psychiatry, 157(1/1).

American Psychiatric Association. (2002). Manual diagnóstico e estatístico de transtornos mentais - DSM-IV-TR (Cláudia Dornelles, Trad.) (4 $4^{\mathrm{a}}$ ed. rev.). Porto Alegre: ArtMed. 
Angermann, K. (1998). Gestalt therapy for eating disorders: an illustration. The Gestalt Journal, 21(1), 19-47.

Antony, S. \& Ribeiro, J. P. (2004). A criança hiperativa: uma visão da abordagem gestáltica. Psicologia: Teoria e Pesquisa [online], 20, n. 2, pp. 127-134. Acesso em 03 de fevereiro de 2008, em http://www.scielo.br/scielo. php?script $=$ sci_arttext $\&$ pid $=$ S0102-37722004000200005 \&lng $=$ pt\&nrm $=$ iso.

Appolinário, J. C. (2000). Transtornos alimentares. Em J. R. Bueno \& A.E. Nardi (Eds.), Diagnóstico e tratamento em psiquiatria (pp. 345-367). Rio de Janeiro: Medsi.

Appolinário, J. C. \& Claudino, A. M. (2000). Transtornos alimentares. Revista Brasileira de Psiquiatria [online]. 22, supl. 2, pp. 28-31. Acesso em 02 de março de 2009, em http:// www.scielo.br/scielo.php?script $=$ sci_arttext\&pid $=$ S1516 $44462000000600008 \& \operatorname{lng}=\mathrm{pt} \& \mathrm{nrm}=\overline{\mathrm{is}}$.

Assumpção Junior, F. B. (2004). Prefácio. Em S. Busse (Org), Anorexia, bulimia e obesidade (pp. 11-14). Barueri: Manole.

Azevedo, A. M. C.; Abuchaim, A. L. G. (1998). Bulimia nervosa: classificação diagnóstica e quadro clínico. Em M. A. Nunes, J. C. Appolinário, A. L. A. Abuchaim \& W. Coutinho, Transtornos alimentares e obesidade (pp. 31-39). Porto Alegre: Artes Médicas.

Beumont, P. J. V. (2002). The clinical presentation of anorexia and bulimia nervosa. Em C. G. Fairburn \& K. D. Brownell (Eds.), Eating disorders and obesity: a comprehensive handbook (pp. 162-170). Nova York: The Guilford Press.

Canguilhem, G. (2000). O Normal e o Patológico. Rio de Janeiro: Forense-Universitária.

Carvalho, L. C. (2008). A intervenção precoce nos ajustamentos do tipo psicótico e a clínica gestáltica: ensaios preliminares. Dissertação de Mestrado em Psicologia Clínica e Cultura, Universidade de Brasília, Brasília. Disponível em: http://bdtd.bce.unb.br/tedesimplificado/tde_busca/arquivo. php?codArquivo $=4124$.

Castro, J. M. \& Goldstein, S. (1995). Eating attitudes and behaviors of pre- and postpubertal females: clues to the etiology of eating disorders. Physiology \& Behavior, 58(1), 15-23.

Cintra, I. P. \& Fisberg, M. (2004). Mudanças na alimentação de crianças e adolescentes e suas implicações para a prevalência de transtornos alimentares. Em Sonia T. Philippi \& Marle Alvarenga (Orgs.), Transtornos alimentares: uma visão nutricional (pp. 149-161). Barueri: Manole.

Cordás, T. A. (2001). Transtornos alimentares em discussão. Revista de Psiquiatria Clínica, 21(4), 178-179.

Cordás, T. A. (2004). Transtornos alimentares: classificação e diagnóstico. Revista de Psiquiatria Clínica, 31(4), 154-157.

Cordás, T. A.; Salzano, F. T. \& Rios, S. R. (2004). Os transtornos alimentares e a evolução no diagnóstico e no tratamento. Em Sonia T. Philippi \& Marle Alvarenga (Orgs.), Transtornos alimentares: uma visão nutricional (pp. 39-62). Barueri: Manole.
Delisle, G. (1991). A Gestalt Perspective of Personality Disorders. The British Gestalt Journal, 1, pp.42-50.

Dietz, W. H. (1990). You are what you eat - what you eat is what you are. Journal of Adolescent Health, 11, 76-81.

Ferreira, A. B. de H. (1993). Minidicionário da Língua Portuguesa. Rio de Janeiro: Nova Fronteira.

Fisher, M., Golden, N. H., Katzman, D. K., Kreipe, R. E., Rees, J., Schebendach, J., Sigman, G., Ammerman, S. \& Hoberman, H. M. (1995). Eating disorders in adolescents: a background paper. Journal of Adolescent Health Care, 16(6), 420-437.

Foucault, M. (1984). Doença Mental e Psicologia. Rio de Janeiro: Tempo Brasileiro.

Foucault, M. (1991). História da Loucura. São Paulo: Perspectiva.

Fromm, E. (1980). Ter ou Ser. Rio de Janeiro: Zahar Editores.

Gaspar, F. M. P. (2004a). Um olhar gestáltico sobre a bulimia nervosa. Trabalho apresentado no X Encontro de Abordagens Terapêuticas Humanistas e Fenomenológicas, Marília, Brasil.

Gaspar, F. M. P. (2004b). O trabalho com pacientes obesos mórbidos no Hospital do Servidor Público Estadual - SP. Trabalho apresentado no X Encontro de Abordagens Terapêuticas Humanistas e Fenomenológicas, Marília, Brasil.

Goffman, E. (1996). Manicômios, Prisões e Conventos. São Paulo: Perspectiva.

Gorgati, S. B.; Holcberg, A. S. \& Oliveira, M. D. (2002). Abordagem psicodinâmica no tratamento dos transtornos alimentares. Revista Brasileira de Psiquiatria, 24(3), 44-48.

Hirschmann, J. R. \& Munter, C. (1992). Adeus às dietas: como superar a compulsão Alimentar num mundo cheio de comida. São Paulo: Saraiva.

Holanda, A. F. (1998). Saúde e Doença em Gestalt-Terapia: aspectos filosóficos. Estudos de Psicologia (Campinas), 15, 2, pp. 29-44.

Holanda, A. F. (2001). Psicopatologia, exotismo e diversidade: ensaio de antropologia da psicopatologia. Psicologia em Estudo [online], Vol. 6, no. 2, pp. 29-38. Acesso em 07 de fevereiro de 2009, em http://www. scielo.br/scielo.php?script $=$ sci_arttext\&pid $=$ S1413$73722001000200005 \& \operatorname{lng}=\mathrm{pt} \& \mathrm{nrm}=$ iso.

Johnson, C. \& Connors, M. E. (1987). The etiology and treatment of bulimia nervosa. New Jersey: Jason Aronson Inc.

Juste, M. (2004). Quando comer é um problema. Revista Galileu. Disponível em http://revistagalileu.globo.com/ Galileu/0,6993,ECT705249-1718,00.html.

Maldonado, M. T. \& Canella, P. (2003). Recursos de relacionamento pra profissionais de saúde: a boa comunicação com clientes e seus familiares em consultórios, ambulatórios e hospitais. Rio de Janeiro: Reichmann \& Affonso Editores.

Manley, R. S.; Rickson, H. \& Standeven, B. (2000). Children and adolescents with eating disorders: strategies for teaching and school conselours. Intervention in school and clinic, 35, 228-231. 
Mattos, J. M. (2000). A visão de saúde e doença da Gestalt-terapia na compreensão da compulsão alimentar. Monografia de Conclusão de Curso. Núcleo de Gestalt-terapia Dialógico. Rio de Janeiro.

Nunes, A. L. (2006). Transtornos Alimentares na visão de meninas adolescentes de Florianópolis: uma visão fenomenológica. Dissertação de Mestrado. Universidade Federal de Santa Catarina. Florianópolis.

Nunes, M. A., Barros, F. C., Anselmo Olinto, M. T., Camey, S. \& Mari, J. D. (2003). Prevalence of abnormal eating behaviours and inappropriate methods of weight control in young women from Brazil: a population-based study. Eating Weight Disorders, 8(2), 1-7.

Panazzolo, M. A. (2002). Distúrbios Alimentares numa Visão Fenomenológica. Revista do VII Encontro Goiano da Abordagem Gestáltica, 8, 114-125.

Perls, F. S., Hefferline, R. \& Goodman, P. (1997). Gestalt-Terapia. São Paulo: Summus.

Pinzon, V. \& Nogueira, F. C. (2004) Epidemiologia, curso e evolução dos transtornos alimentares. Revista de Psiquiatria Clínica, 31(4), 158-160.

Polito, F. M. (1999). A polaridade saudável do processo do adoecer. [citado 23 Março 2005]. Disponível em: http://www. fronteirasgestalticas.com.br/artigos.asp?codigo $=5$.

Ribeiro, J. P. (1985). Gestalt Terapia: refazendo um caminho. São Paulo: Summus.

Rodrigues, H. E. (2000). Introdução à Gestalt Terapia: conversando sobre os fundamentos da abordagem gestáltica. Petrópolis: Vozes.

Saikali, M. O. J. (2004). Atendimento familiar. Trabalho apresentado no X Encontro de Abordagens Terapêuticas Humanistas e Fenomenológicas, Marília, Brasil.

Teixeira, M. J. (2004a). Fome de vida: a psicoterapia com pacientes com transtornos alimentares. Trabalho apresentado no X Encontro de Abordagens Terapêuticas Humanistas e Fenomenológicas, Marília, Brasil.

Teixeira, M. J. (2004b). Anorexia nervosa. Trabalho apresentado no X Encontro de Abordagens Terapêuticas Humanistas e Fenomenológicas, Marília, Brasil.

Teixeira, M. J. (2005). Fome de vida: a obesidade feminina à luz da Gestalt-terapia. Em L. M. Frazão \& S. L. C. O. Rocha (Orgs.), Gestalt e gênero: configurações do masculino e do feminino na contemporaneidade (pp. 35-75.). Campinas: Livro Pleno.

Tellegen, T. A. (1984). Gestalt e grupos: uma perspectiva sistêmica. São Paulo: Summus.

Tenório, C. M. D. (2003). Os Transtornos da Personalidade Histriônica e Obsessiva-Compulsiva na Perspectiva da Gestalt-Terapia e da Teoria de Fairbairn. Dissertação de Mestrado em Psicologia Clínica, Universidade de Brasília, Brasília.
Arlene Leite Nunes - Psicóloga Clínica, Especialista em Gestalt-terapia, Mestre em Nutrição pela Universidade Federal de Santa Catarina, Professora e Supervisora de Estágio de Psicologia Clínica na Universidade da Região de Joinville (Univille) e Professora no Instituto Superior Tupy (IST/SOCIESC). Endereço para correspondência: Rua Luiz Delfino, 719/603. Bairro Glória. Joinville/SC. CEP 89216.120.

Email: arlenenunes@gmail.com

Adriano Holanda - Doutor em Psicologia e Professor Adjunto da Universidade Federal do Paraná. Endereço para correspondência: Departamento de Psicologia, Universidade Federal do Paraná, Praça Santos Andrade, 50 - Sala 215 (Ala Alfredo Buffren). CEP 80060.240 - Curitiba/PR.

Email: aholanda@yahoo.com

Recebido em 18.06.08 Primeira Decisão Editorial em 15.07.08 Aceito em 20.02.09 